\title{
Lennox Gastaut Syndrome: A Case Report
}

\section{Shrestha $\mathrm{M}^{1}$, Shrestha $\mathrm{L}^{2}$, Shrestha $\mathrm{PS}^{3}$}

${ }^{1}$ Dr. Merina Shrestha, MBBS, MD, Teaching Assistant, ${ }^{2}$ Dr. Laxman Shrestha MBBS, MD, Associate Professor, ${ }^{3}$ Prof. Prakash Sundar Shrestha, Department of Child Health, (Institute of Medicine) Tribhuvan University Teaching Hospital, Kathmandu, Nepal.

Address for Correspondence: Dr. Merina Shrestha, E-mail: shresthamerina@hotmail.com

\begin{abstract}
Lennox-Gastaut syndrome (LGS) is a severe form of childhood epilepsy that is defined by generalized multiple type seizures, slowness of intellectual growth, and a specific EEG disturbance. Children affected might previously have infantile spasms or underlying brain disorder but etiology can be idiopathic. LGS seizures are often treatment resistant and the long term prognosis is poor.
\end{abstract}

Key words: epilepsy, intellectual growth

\section{Case}

six year old boy with normal premorbid development - ivas brought for evaluation of seizure occurring since the age of 18 months. Initially he used to have generalized tonic clonic convulsion, several episodes in a day; however over a period of five years he developed multiple types of seizure: myoclonic jerks, drop attacks and absence seizures. He had been treated without success with multiple anti-epileptic drugs including phenobarbitone, phenytoin, carbamazepine and valproate. At the time of presentation, he was having 7-8 episodes of seizure a day and was on valproate $25 \mathrm{mg} / \mathrm{kg}$, carbamazepine $6 \mathrm{mg} / \mathrm{kg}$ and clonazepam 0.08 $\mathrm{mg} / \mathrm{kg}$.

Detailed history revealed that he was born fullterm at hospital. Antenatal, perinatal and postnatal history was insignificant. On examination, there was no dysmorphism. His head circumference was $52 \mathrm{~cm}$. There was multiple scar over his scalp but there were no neurocutaneous markers. During examination, he had several absence seizures. Rest of the general and systemic examinations were also normal except that he had a stooping gait with short steps. He used to utter few obscene words. His vision and hearing were also normal.

Investigations revealed normal fundus, a normal MRI brain and baseline metabolic profile. EEG showed sharp slow waves (Fig 1). He was diagnosed as LGS as he met the three most important criterions for diagnosis which included multiple types of generalized seizures, which are difficult to control, slowness of intellectual growth and specific EEG findings.

The dose of valproate was increased to $45 \mathrm{mg} / \mathrm{kg}$ and clonazepam to $0.15 \mathrm{mg} / \mathrm{kg}$. Carbamazepine was stopped. The seizure was controlled at the time of discharge.

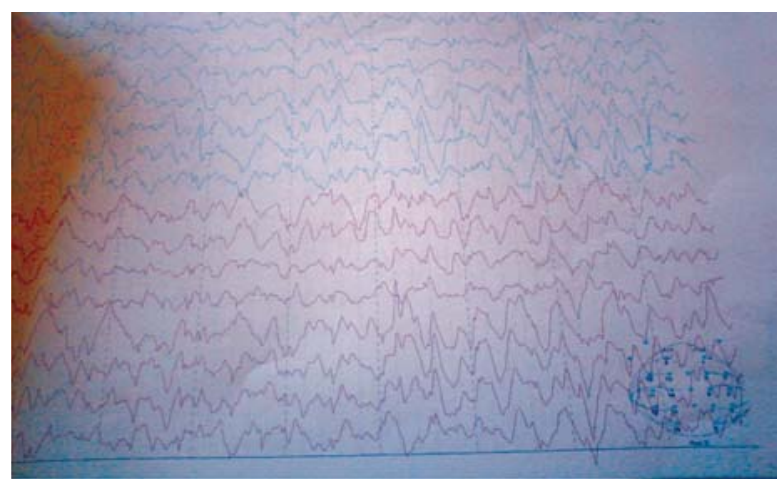

Fig. 1: EEG showing sharp slow waves

\section{Discussion}

LGS is one of the catastrophic childhood epilepsies. It is defined by a triad of symptoms: Multiple types of generaslized seizures, which are difficult to control; slowness of intellectual growth often accompanied by mental retardation and behavioural problems and 
specific electroencephalogram (EEG) pattern called a slow spike and wave pattern $(<2.5 \mathrm{~Hz})$, which is present when the child is awake ${ }^{1-4}$.

William Lennox described the clinical features of the syndrome in 1930s, and then Lennox and Davis reported the symptomatic triad of the syndrome. Later, Gastaut expanded on the original observations of Lennox and Davis ${ }^{5-6}$ In addition, the Commission on Classification and Terminology of the International League Against Epilepsy described the criteria of LGS and their frequency are: (1) diffuse slow spike waves in the EEG (100\%). (2) Tonic seizures (94\%), (3) atypical absences (80\%), (4) runs of rapid spikes in NREM sleep (approx. 70\%), (5) status epilepticus (60\%), (6) atonic seizures (43\%). Resistance to therapy and persistence of epilepsy are amongst the most frequent features. Mental retardation is a leading symptom, occurring on average in $90 \%$ of cases ${ }^{7}$.

\section{Prevalence}

LGS accounts for $1-4 \%$ of patients with childhood epilepsy. The prevalence of LGS in Atlanta, Georgia, was reported as 0.26 per 1000 live births. Epidemiologic studies in the western or industrialized world (Israel, Spain, Estonia, Italy, Finland) demonstrated that the proportion of patients with LGS seems relatively consistent across the populations studied and similar to that in the United States ${ }^{8}$. There is no such studies carried out in this part but a study done in AIIMS, India by $\mathrm{V}$ Karla et al has shown that $3.5 \%$ of the children attending neurology clinic were suffering from epileptic encephalopathy including LGS 9 .

The mean age onset of seizure is $26-28$ months (range, $1 \mathrm{~d}$ to $14 \mathrm{y}$ ). The peak age at epilepsy onset is older in patients with LGS of an identifiable etiology than in those whose LGS has no identifiable etiology. They rarely start after the age of eight ${ }^{2,3}$.

\section{Etiology}

In about one third of the affected children cause cannot be identified. These cases are referred to as cryptogenic LGS ${ }^{2,3}$. On the other side, many of the children who develop LGS had a pre-existing brain disorder or injury. Causes identified include tuberous sclerosis, congenital infections, hereditary metabolic diseases, brain malformation, and brain damage (due to birth asphyxia or other birth injuries, encephalitis, meningitis or head injuries). In a study of childhood recurrent seizures in Red Cross memorial hospital in Cape Town, South Africa, $11 \%$ suffered from menigities or encephalitis as a precipitating factor and $55 \%$ were intellectually handicapped ${ }^{10}$.

\section{Clinical features}

Typically, daily multiple seizure types occur in LGS. Of them, tonic seizures occur more frequently and are often nocturnal. Children may have atonic, myoclonic, partial, tonic-clonic or absence seizures. Additionally, about $60 \%$ of children may have status epilepticus ${ }^{13}$. Most children with the Lennox-Gastaut syndrome have intellectual impairment and learning disability that ranges from mild to severe. Behavioral problems and depression are also common, which can be attributed to the brain injury, the frequent seizures, and the lack of normal social stimulation or as side effects of AntiEpilepticDrugs (AEDs) ${ }^{5,11}$. These children are also more likely to have cerebral palsy, progressive decline in IQ and progressive gait disturbances ${ }^{5}$. They may look irritable, tired or bored. Many children fail to cope with school and need institutional care. The child's development is rarely normal. The seizures can cause sudden falls and/or loss of balance, and patients are advised to wear a helmet to prevent head, face and teeth injury.

The diagnosis of LGS thus depends on the clinical manifestation and typical EEG finding characterized by an interictal EEG disturbance of slow spike-wave pattern $(<2.5 \mathrm{~Hz})$, often accompanied by a burst of fast rhythms of 10 to $12 \mathrm{~Hz}$ at night ${ }^{1-3}$.

\section{Treatment}

The optimum treatment for Lennox-Gastaut syndrome has yet to be established ${ }^{12}$. Pharmacological treatment consists mainly of one or multiple antiepileptic drugs (AED's). No single treatment regimen could be considered superior to the others, and management depends on the response of the patients. Medical treatment usually starts with valproates followed by adjunctive therapy with either lamotrigine or topiramate ${ }^{13,14}$.

Most epileptologists have viewed valproate as a first-line drug for LGS since the early 1980's because of: (1) VPA's efficacy against partial seizures and generalized seizures (including absence); (2) lack of exacerbation of any of the seizure types associated with LGS; (3) relative lack of sedative side-effects compared to barbiturates, and (4) relative ease of use compared to the ketogenic diet.

In cases of intractable seizures surgical treatments like vagus nerve stimulation, corpus callosotomy and Electrical stimulation of the centromedian thalamic nucleus are reported to be effective in few cases.

Ketogenic diet is a reportedly effective option for treatment. A ketogenic diet is a high fat, low protein, low 
carbohydrates diet that induces ketosis, a state in which there is an excessive amount of ketones in the body. It is very effective and is becoming increasingly popular for treatment of LGS.

\section{Goals and Treatment Objectives}

Counseling of the parents or caregiver regarding the nature of the disease is the important part of the treatment. Children with LGS never become seizure free and the goal is to limit the number of seizures while maintaining alertness. The seizures that result in falls and injuries and the atypical absence seizures (that exacerbate the epileptic encephalopathy) should be the primary therapeutic target. Limiting the doserelated sedative and cognitive side effects may improve quality of life for the patient and lastly relative remissions and exacerbations of seizure frequency that are often unrelated to any obvious external factors; quick decisions that lead to discontinuing a drug or adding an additional drug may be regreted later. For clusters of seizures benzodiazepines (rectal diazepam or sublingual/oral lorazepam) can be used.

\section{Prognosis}

The long term outcome is poor in terms of seizure control and intellectual development. Catastrophic disorders such as LGS are associated with morbidity and mortality ${ }^{1}$. Eighty percent of patients with LennoxGastaut syndrome continue to have seizures throughout childhood and into their adult life. The mortality rate ranges from 3 to $7 \%^{2}$.

\section{References}

1. Shields WD. Diagnosis of Infantile Spasms, Lennox -Gastaut Syndrome and Progressive Myoclonic Epilepsy. Epilepsia 2004;45:2-4

2. Crumrine PK.Lennox GAstaut syndrome. J Child Neurol.2002:70-75

3. Markland ON. Lennox GAstaut syndrome (childhood epileptic encephalopathy). J Clin Neurophysiol.2003;20:426-441

4. Heiskala H.Community-based study of Lennox GAstaut syndrome. Epilepsia 1997;38:526-531

5. Trevathan, E. Infantile Spasms and Lennox-Gastaut Syndrome. J Child Neurol. 2002; 17:9-22.

6. Gastaut, H; Roger, J; Soulayrol, R; Tassinari, CA; Regis, H; Dravet, C. Childhood epileptic encephalopathy of children with diffuse slow spikewaves (otherwise known as "petit mal variant") or Lennox syndrome. Epilepsia. 1966; 7:139-179.

7. Hirt HR.Nosology of Lennos GAstaut syndrome. Nevernazt;1996 Feb 67(2);109-22

8. Trevathan, E; Murphy, CC; Yeargin-Allsopp, M. Prevalence and descriptive epidemiology of Lennox-Gastaut syndrome among Atlanta children. Epilepsia. 1997; 38:1283-1288.

9. V Karla, S Gulati, PAndey RM et al. West syndrome and other Infantile epileptic encephaloparthy-Indian Hospital experience. Brain Dev 2002;24:130-139

10. Leary, PM; Riordan, G; Schlegel, B; Morris, S. Childhood secondary (symptomatic) epilepsy, seizure control, and intellectual handicap in a nontropical region of South Africa. Epilepsia. 1999; 40:1110-1113.

11. Schmidt, D; Bourgeois, B. A Risk-Benefit Assessment of Therapies for Lennox-Gastaut Syndrome. Drug Saf. 2000;22:467-477

12. Hancock E, Cross H. Treatment of Lennox-Gastaut syndrome. Cochrane Database of Systematic Reviews 2003, Issue 3.

13. Timmings PL, Richens A. Lamotrigine as addon drug in the management of Lennox-Gastaut syndrome. Eur Neurol 1992; 32:305-307.

14. Ritter FJ, Glauser TA, Sachdeo RC, Shu-Chen W. Long-term experience with topiramate in LennoxGastaut syndrome. Epilepsia 1998; 39:2-3. Abstract.

15. McLachlan RS. Vagus nerve stimulation for intractable epilepsy: a review. J Clin Neurophysiol 1997; 14:358-368.

16. Sorenson JM, Wheless JW, Baumgartner JE, Thomas AB, Brookshire BL, Clifton GL, et al. Corpus callosotomy for medically intractable seizures. Pediatr Neurosurg 1997; 27:260-267.

17. Velasco, AL; Velasco, F; Jiménez, F; Velasco, M; Castro, G; Carrillo-Ruiz, JD; Fanghänel, G; Boleaga, B. Neuromodulation of the centromedian thalamic nuclei in the treatment of generalized seizures and the improvement of the quality of life in patients with Lennox-Gastaut syndrome. Epilepsia. 2006;47:1203-1212 